\title{
Redistribution of Cerebral Blood Flow during Severe Hypovolemia and Reperfusion in a Sheep Model: Critical Role of $\alpha 1$-Adrenergic Signaling
}

\author{
René Schiffner ${ }^{1,2, *, \dagger}$, Sabine Juliane Bischoff ${ }^{3, \dagger}$, Thomas Lehmann ${ }^{4}$, Florian Rakers ${ }^{2}$, \\ Sven Rupprecht ${ }^{2}$, Juliane Reiche ${ }^{5}$, Georg Matziolis ${ }^{1}$, Harald Schubert ${ }^{3}$, Matthias Schwab ${ }^{2}$, \\ Otmar Huber ${ }^{5}$ and Martin Schmidt ${ }^{5}$ \\ 1 Orthopedic Department, Campus Eisenberg, Jena University Hospital-Friedrich Schiller University, \\ 07607 Eisenberg, Germany; G.Matziolis@krankenhaus-eisenberg.de \\ 2 Department of Neurology; Jena University Hospital-Friedrich Schiller University, 07743 Jena, Germany; \\ Florian.Rakers@med.uni-jena.de (F.R.); Sven.Rupprecht@med.uni-jena.de (S.R.); \\ Matthias.Schwab@med.uni-jena.de (M.S.) \\ 3 Institute for Laboratory Animal Sciences and Welfare, Jena University Hospital-Friedrich Schiller University, \\ 07743 Jena, Germany; Sabine.Bischoff@med.uni-jena.de (S.J.B.); harald.schubert@outlook.de (H.S.) \\ 4 Institute of Medical Statistics, Computer Sciences and Documentation Science, Jena University \\ Hospital-Friedrich Schiller University, 07743 Jena, Germany; thomas.lehmann@med.uni-jena.de \\ 5 Institute for Biochemistry II, Jena University Hospital-Friedrich Schiller University, 07743 Jena, Germany; \\ Juliane.Reiche@med.uni-jena.de (J.R.); Otmar.Huber@med.uni-jena.de (O.H.); \\ Martin.Schmidt@med.uni-jena.de (M.S.) \\ * Correspondence: rene.schiffner@med.uni-jena.de; Tel.: +49-36691-81292; Fax: +49-36691-81029 \\ + These authors contributed equally to this work.
}

Academic Editor: Kuniaki Ogasawara

Received: 22 March 2017; Accepted: 8 May 2017; Published: 11 May 2017

\begin{abstract}
Background: Maintenance of brain circulation during shock is sufficient to prevent subcortical injury but the cerebral cortex is not spared. This suggests area-specific regulation of cerebral blood flow (CBF) during hemorrhage. Methods: Cortical and subcortical CBF were continuously measured during blood loss $(\leq 50 \%)$ and subsequent reperfusion using laser Doppler flowmetry. Blood gases, mean arterial blood pressure (MABP), heart rate and renal blood flow were also monitored. Urapidil was used for $\alpha 1 \mathrm{~A}$-adrenergic receptor blockade in dosages, which did not modify the MABP-response to blood loss. Western blot and quantitative reverse transcription polymerase chain reactions were used to determine adrenergic receptor expression in brain arterioles. Results: During hypovolemia subcortical CBF was maintained at $81 \pm 6 \%$ of baseline, whereas cortical CBF decreased to $40 \pm 4 \%(p<0.001)$. Reperfusion led to peak CBFs of about $70 \%$ above baseline in both brain regions. $\alpha 1 \mathrm{~A}$-Adrenergic blockade massively reduced subcortical $\mathrm{CBF}$ during hemorrhage and reperfusion, and prevented hyperperfusion during reperfusion in the cortex. $\alpha 1 \mathrm{~A}-\mathrm{mRNA}$ expression was significantly higher in the cortex, whereas $\alpha 1 \mathrm{D}-\mathrm{mRNA}$ expression was higher in the subcortex $(p<0.001)$. Conclusions: $\alpha 1$-Adrenergic receptors are critical for perfusion redistribution: activity of the $\alpha 1 \mathrm{~A}$-receptor subtype is a prerequisite for redistribution of $\mathrm{CBF}$, whereas the $\alpha 1 \mathrm{D}$-receptor subtype may determine the magnitude of redistribution responses.
\end{abstract}

Keywords: adrenergic regulation; alpha-adrenergic; cerebral blood flow; cerebral hemodynamics; resuscitation; head trauma; cerebrovasvular disease; neurodegenerative disease 


\section{Introduction}

Severe bleeding (hemorrhage) is a common cause of disability following traumatic ruptures of large vessels and parenchymal organs, gastrointestinal bleeding or placenta abruption [1-5]. The sub-population most at risk for severe trauma and hemorrhage are people under 45 years [1]. The long-term functional outcome is largely determined by the degree of brain damage resulting from shock-associated cerebral hypoperfusion [6,7]. Although redistribution mechanisms maintain cerebral perfusion constant over a wide range of reduced blood pressures [8], this centralization of the circulation under shock conditions does not effectively prevent from cerebral injury [9]. The cerebral cortex appears to be the most vulnerable brain structure under severe shock conditions [7,9]. The origin of this vulnerability remains unclear. It is generally attributed to (1) high susceptibility of cortical neurons to ischemia or (2) to insufficient maintenance of cortical perfusion compared to subcortical structures [10-12]. Resolving this issue will be of crucial importance for clinical medicine since it may lead to development of new strategies for attenuating cortical damage during shock. Here we tested the hypothesis that the effectiveness of cerebral redistribution mechanisms under clinically relevant conditions (hemorrhagic shock) is inferior in the phylogenetic younger cerebral cortex than in the phylogenetically older subcortex, which contains vital regions such as the respiration and circulation control centers. The plausibility of this hypothesis is supported by some evidence for differences in cerebral blood supply in different brain regions [13]. We used a sheep model of hypovolemia since several features of this animal model like body weight, blood volume, cerebral gyration and cerebral vascular supply are similar to humans. Importantly, we continuously measured cerebral blood flow (CBF) during blood loss and reperfusion in the cortex and subcortical areas. In contrast, CBF has been monitored discontinuously in previous studies using experimental shock models [14-16], an approach that has possibly led to gaps in the understanding of cerebral perfusion maintenance during hypovolemia.

We further considered the possibility that regional differences in $\alpha 1$-adrenergic receptor densities exist and that these differences enable region-specific maintenance of cerebral perfusion during severe hemorrhage. Evidence for different levels of $\alpha 1$-adrenergic receptor expression in brain blood vessels have not been presented up to now (to our knowledge). However, two general considerations seemed to justify our adrenergic hypothesis. First, the $\alpha 1$-adrenergic system is the major vasoconstrictory effector of sympathetic activation during hemorrhagic shock [17]. And second, a lower concentration of $\alpha 1$-adrenergic receptors in the cerebral than in the peripheral circulation prevents from cerebral vasoconstriction during severe hemorrhage and is critically involved in cerebral blood supply $[18,19]$. We tested the role of the $\alpha 1$-adrenergic system by applying the specific blocker urapidil and continuously measuring CBF during subsequent blood loss and reperfusion.

\section{Results}

\subsection{Effects of Severe Hemorrhage on Arterial Blood Gases and Vital Parameters}

Arterial blood gases and lactate were within their physiological ranges before the onset of controlled hemorrhage and after reperfusion (Figure 1). Hemorrhage induced a decrease of $\mathrm{pH}$ and $\mathrm{pO}_{2}$, and an increase of $\mathrm{pCO}_{2}$ and lactate $(p<0.05$, Figure 1). Reperfusion could not normalize $\mathrm{pH}$ and $\mathrm{pCO}_{2}$, whereas $\mathrm{pO}_{2}$ was restored to baseline after reperfusion. The increase of lactate and the decrease of base excess were exaggerated after reperfusion. Oxygen saturation was unchanged during the course of the experiments. 
A

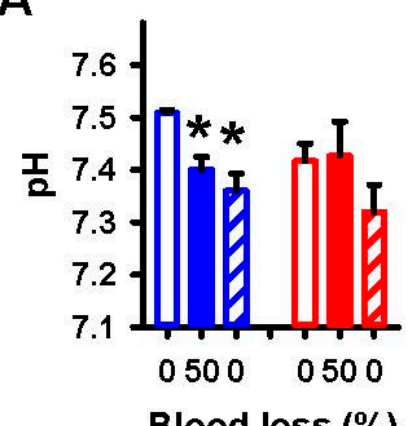

Blood loss (\%)

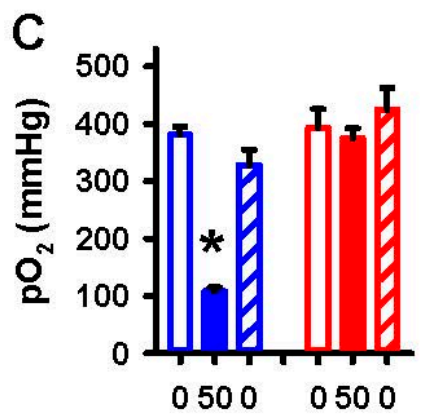

Blood loss (\%)

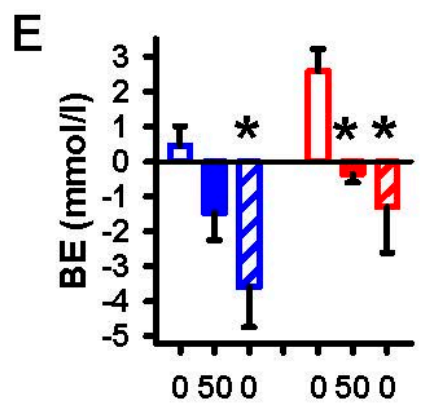

Blood loss (\%)
B
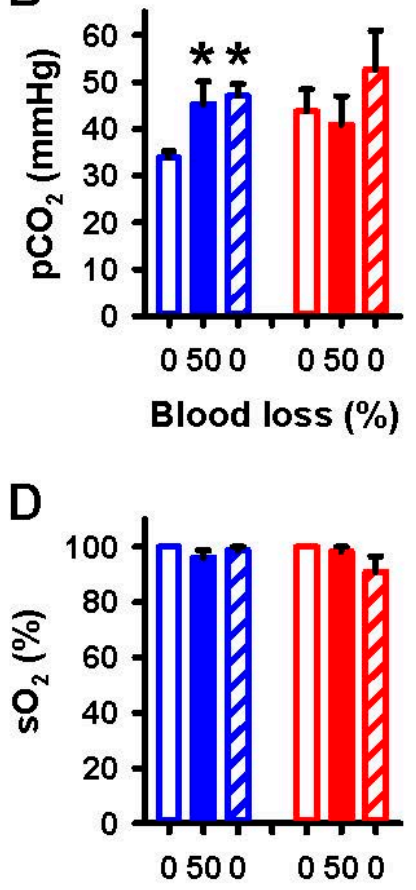

Blood loss (\%)

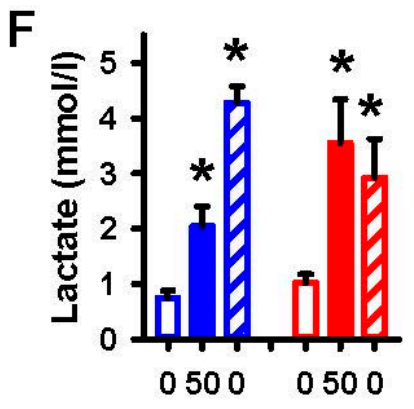

Blood loss (\%)

Figure 1. Effects of 50\% blood loss and reperfusion on arterial blood gases and lactate. Values are given for baseline (open bars), removal of $50 \%$ blood (filled bars) and complete reperfusion (hatched bars) in controls (blue) and after $\alpha 1 \mathrm{~A}$-adrenergic blockade (red) for (A) $\mathrm{pH},(\mathbf{B})$ partial pressure of carbon dioxide $\left(\mathrm{pCO}_{2}\right),(\mathbf{C})$ partial pressure of oxygen $\left(\mathrm{pO}_{2}\right),(\mathbf{D})$ oxygen saturation $\left(\mathrm{sO}_{2}\right),(\mathbf{E})$ base excess $(\mathrm{BE})$ and $(\mathrm{F})$ lactate. Mean $\pm \mathrm{SEM} ;{ }^{*} p<0.05$ compared to baseline.

Fifty percent loss of blood volume induced a decrease in mean arterial blood pressure (MABP) from $71 \pm 3 \mathrm{mmHg}$ to $14 \pm 1 \mathrm{mmHg}(p<0.001)$, an increase of heart rate (HR) from $87 \pm 5 \mathrm{bpm}$ to $133 \pm 9 \mathrm{bpm}(p<0.001)$ and a decrease in renal blood flow (RBF) from $91 \pm 7 \mathrm{~mL} / \mathrm{min}$ to $3 \pm 2 \mathrm{~mL} / \mathrm{min}$ ( $p=0.008$; Figure 2). Reperfusion restored the MABP to $68 \pm 2 \mathrm{mmHg}$ and the HR to $93 \pm 10 \mathrm{bpm}$, neither of which were different from baseline values at the end of the recovery period (Figure 2). The RBF reached $79 \pm 4 \mathrm{~mL} / \mathrm{min}$, still $14 \%$ below baseline. 

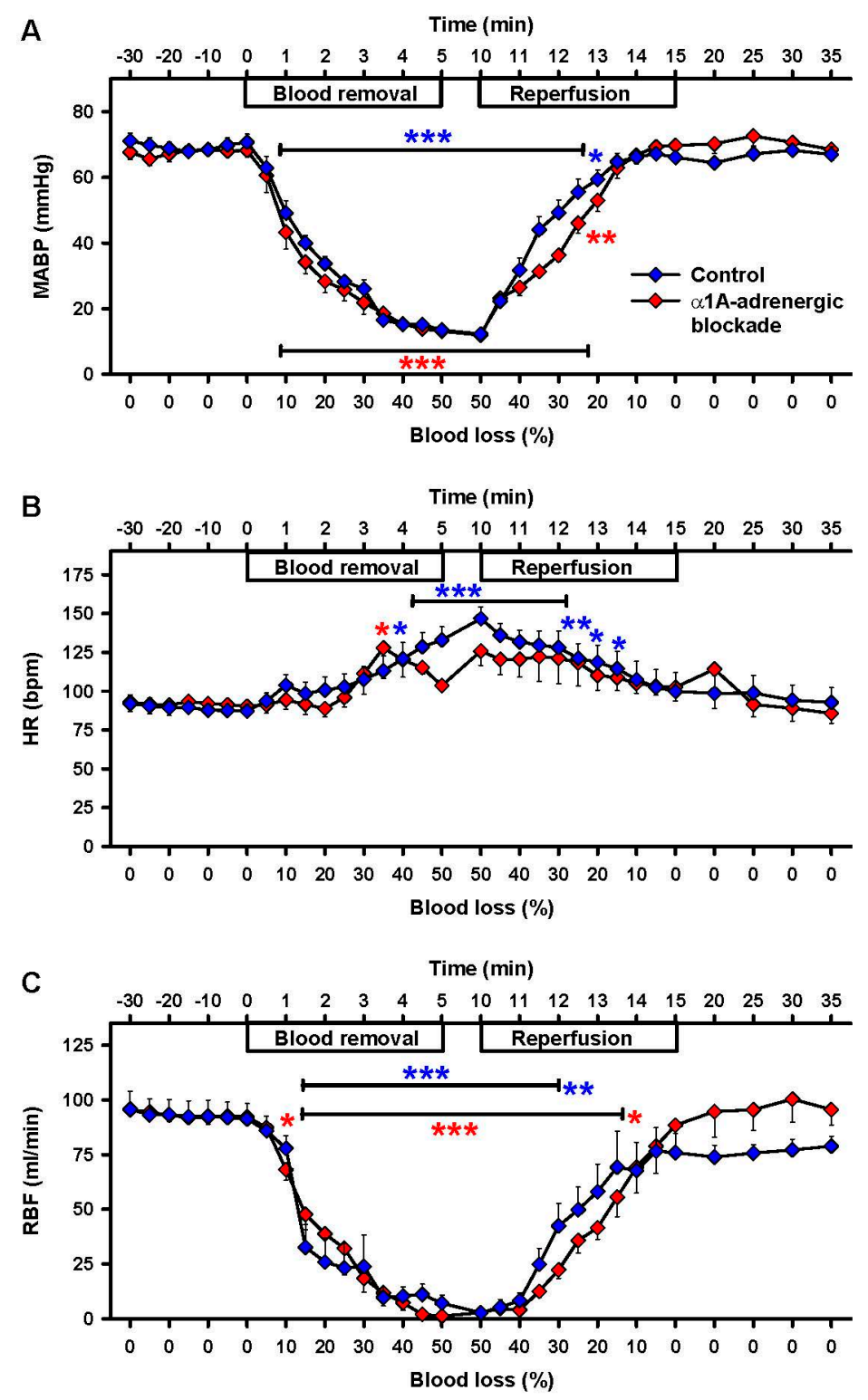

Figure 2. Effects of $50 \%$ blood loss and reperfusion on vital parameters. (A) Mean arterial blood pressure (MABP), (B) heart rate (HR) and (C) renal blood flow (RBF). Controls in blue and $\alpha 1 \mathrm{~A}$-adrenergic blockade in red. Mean $\pm \mathrm{SEM}^{*} p<0.05,{ }^{* *} p<0.01$ and ${ }^{* * *} p<0.001$ compared to baseline.

\subsection{Effects of Severe Hemorrhage on $C B F$}

Cortical CBF remained constant until a blood loss of $10 \%$. Subsequently it decreased to $40 \pm 4 \%$ of baseline at a blood loss of 50\% ( $p<0.001$, Figure 3A). In contrast, subcortical CBF remained constant until a blood loss of $20 \%$ and subsequently decreased to $81 \pm 6 \%$ of baseline at a blood loss of $50 \%$ $(p<0.001$, Figure 3A). The slope of the cortical CBF decrease was more than three-fold higher than the slope of the subcortical CBF decrease (calculated by a linear model; $6.3 \%$ versus $1.7 \%$ loss of blood flow per min over $10 \mathrm{~min}$ after start of blood removal; $p<0.001$ ).

Reperfusion of $10 \%$ blood was sufficient to restore subcortical CBF to baseline, whereas $25 \%$ blood reperfusion was needed to reach baseline levels for cortical CBF. Complete replenishment of blood volume led to significantly elevated cortical CBF, reaching a maximum of $172 \pm 30 \%$ (Figure $3 \mathrm{~A}$ ). Subcortical CBF increased faster, reaching a maximum of $171 \pm 26 \%$ (Figure 3A) and fell back to baseline $20 \mathrm{~min}$ after restoration of the initial blood volume. The important finding of this study is that 
the responses of cortex and subcortex to blood loss started to differ significantly when $20 \%$ or more blood were lacking (Figure 3A).
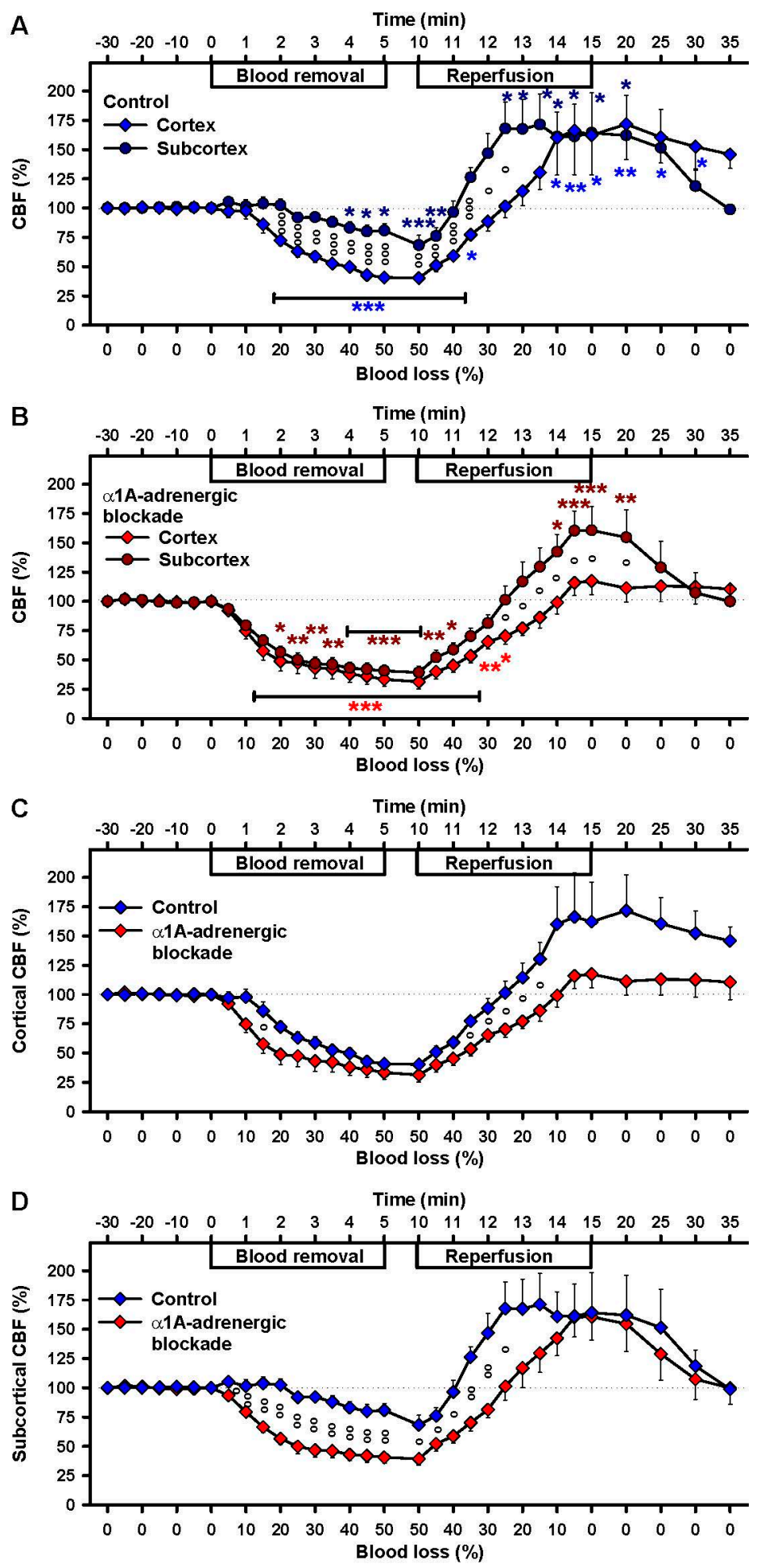

Figure 3. Effects of $50 \%$ blood loss and reperfusion on cortical and subcortical cerebral blood flow (CBF). Comparison of cortical and subcortical CBF in the control group (A) and under $\alpha 1 \mathrm{~A}$-adrenergic blockade (B). Comparison of controls and $\alpha 1 \mathrm{~A}$-adrenergic blockade for (C) cortex and (D) subcortex. Means \pm SEM; ${ }^{*} p<0.05,{ }^{* *} p<0.01$ and ${ }^{* * *} p<0.001$ compared to baseline; ${ }^{\circ} p<0.05,{ }^{\circ \circ} p<0.01$ and ${ }^{\circ 00} p<0.001$ for comparison between two experimental groups. 


\subsection{Correlation of Blood Flow and $M A B P$}

To test the relationship of blood flow and MABP, region-specific blood flow was plotted versus MABP. Data were plotted for the blood removal phase (Figure 4A-C) and for the reperfusion phase (Figure 4D-F) separately. For all data sets (cortical CBF, subcortical CBF or RBF; during blood removal or reperfusion), three-parameter logistic regression curves with highly significant correlations for blood flow and MABP could be fitted to the data (Figure 4; correlation coefficients are given in the respective panels; $p<0.00001$ for all data sets). While there resulted an almost linear curve for RBF, the curves for both cortical and subcortical CBF indicate redistribution of blood flow (Figure 4A-C). Apparently, redistribution is fully effective only in the subcortex. Nearly linear curve fits were obtained during reperfusion for the three tissues measured (Figure 4D-F).
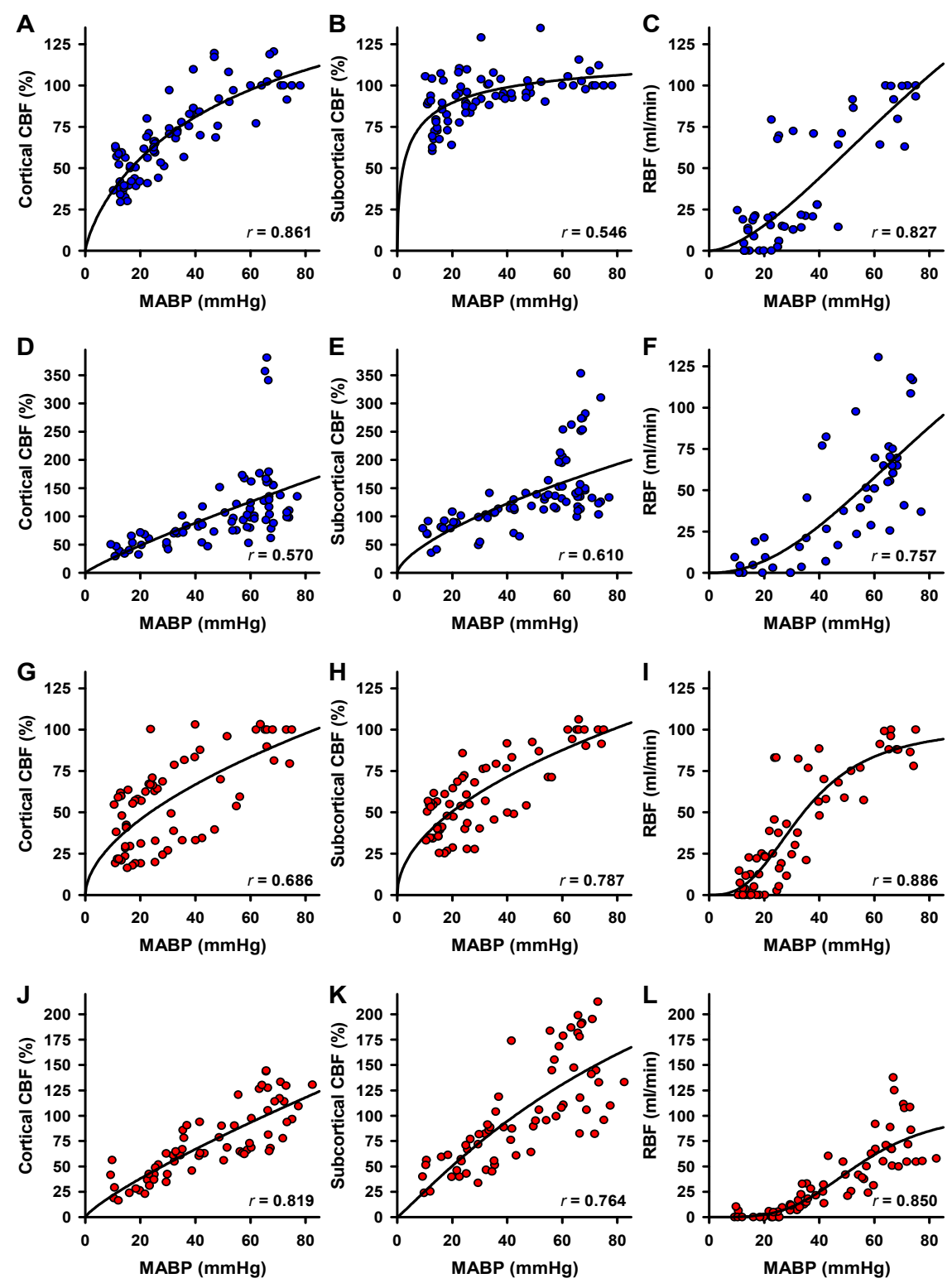

Figure 4. Correlation of blood flow and MABP. Cortical or subcortical CBF or RBF in the control group (blue symbols) were plotted against MABP during blood withdrawal $(\mathrm{A}-\mathrm{C})$ and for the reperfusion phase (D-F), respectively. The effect of $\alpha 1 \mathrm{~A}$-adrenergic blockade (red symbols) on the relationships of blood flow and MABP during blood withdrawal (G-I) or during reperfusion (J-L) is plotted analogously. Three-parameter logistic regression was calculated for each data set (solid lines). Correlation coefficients $(r)$ are given in the respective panels, $p<0.00001$ for all data sets. 


\subsection{Effects of $\alpha 1$ A-Adrenergic Blockade}

Under $\alpha 1 \mathrm{~A}$-adrenergic blockade with urapidil there were no significant alterations measured for $\mathrm{pH}, \mathrm{pCO}_{2}, \mathrm{pO}_{2}$ and $\mathrm{sO}_{2}$, whereas the decrease in $\mathrm{BE}$ and the increase of lactate were similar to the control group $(p<0.05$, Figure 1E,F) during hemorrhage and reperfusion. The low dosage chosen for $\alpha 1 \mathrm{~A}$-adrenergic blockade did not affect MABP and HR at baseline and during hemorrhage and subsequent reperfusion. RBF was indistinguishable from controls during hemorrhage but in contrast to controls was restored to baseline after reperfusion (Figure 2C).

In the presence of urapidil the decrease of cortical CBF to $31 \pm 6 \%$ of baseline paralleled the decrease of subcortical CBF to $39 \pm 5 \%$ (both $p<0.001$, Figure 3B). Subsequent reperfusion of $40 \%$ blood restored cortical CBF to baseline, which was not exceeded significantly over time. In contrast, in the subcortex an equal degree of reperfusion resulted in CBF significantly exceeding baseline (peak at complete reperfusion, $161 \pm 20 \%, p<0.001$, Figure 3B). This observation shows for the first time that blood flow in cortex and subcortex is significantly different during reperfusion when $\alpha 1 \mathrm{~A}$-adrenergic receptors are blocked (Figure 3B).

In cortical CBF-responses, the $\alpha 1 \mathrm{~A}$-adrenergic blockade exerts its effect mainly during reperfusion: it prevents the hyper-perfusion observed during restoration of the blood volume (Figure 3C). Interestingly, in the subcortex the CBF-response to blood loss in the presence of urapidil was significantly stronger than in the control group during hemorrhage and reperfusion (Figure 3D). In addition, hyperperfusion was delayed but not prevented during reperfusion.

Under $\alpha 1 \mathrm{~A}$-adrenergic blockade correlation analysis for cortical CBF, subcortical CBF or RBF, respectively, in relation to MABP revealed no difference between the brain regions during hemorrhage (Figure 4G-I; $p<0.00001$ for all data sets). As seen in the control animals, nearly linear curve fits were obtained during reperfusion for the three tissues measured (Figure 4J-L).

\subsection{Expression of $\alpha 1$-Adrenergic Receptors}

Brain arterioles from the cortex and subcortex showed no difference in the expression of $\alpha 1$-adrenergic receptors ( $\alpha 1$-AR) at the protein level (Figure $5 \mathrm{~A}$ ) in both brain regions under investigation (Figure 5B). Quantitative RT-PCR was used to definitively clarify which $\alpha 1$-AR subtypes are expressed in brain arterioles of the cortex and subcortex. In both brain regions mRNA-expression for $A D R A 1 A$ and $A D R A 1 D$ was found, whereas $A D R A 1 B$ was not expressed (Figure 5C). Interestingly, $A D R A 1 A$ expression in cortical arterioles is significantly stronger than in subcortical arterioles, whereas expression of $A D R A 1 D$ is significantly stronger in subcortical arterioles (Figure 5D). This expression pattern was not dependent on the gene used for normalization-a prototypical housekeeping gene $(G A P D H)$ or an endothelial marker (ZO-1).

A

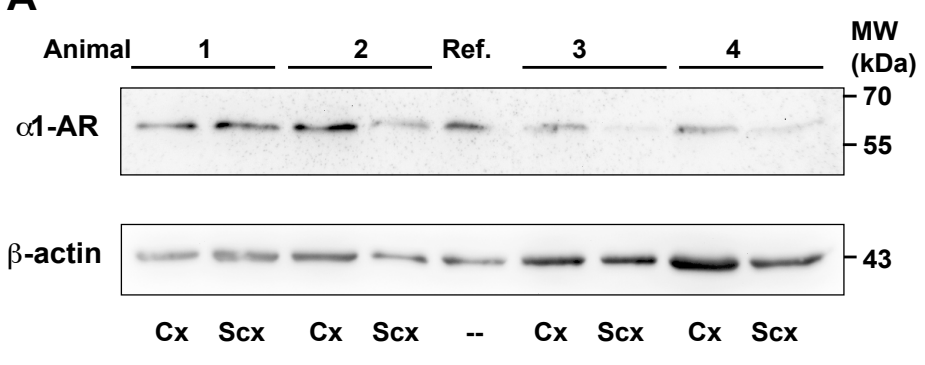

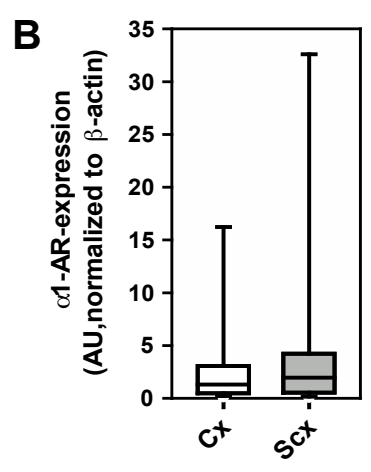

Figure 5. Cont. 
C
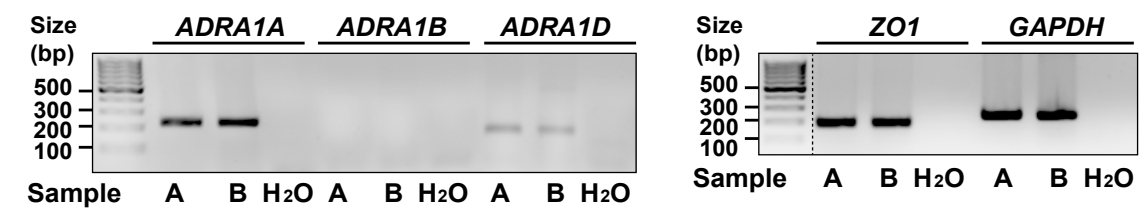

D
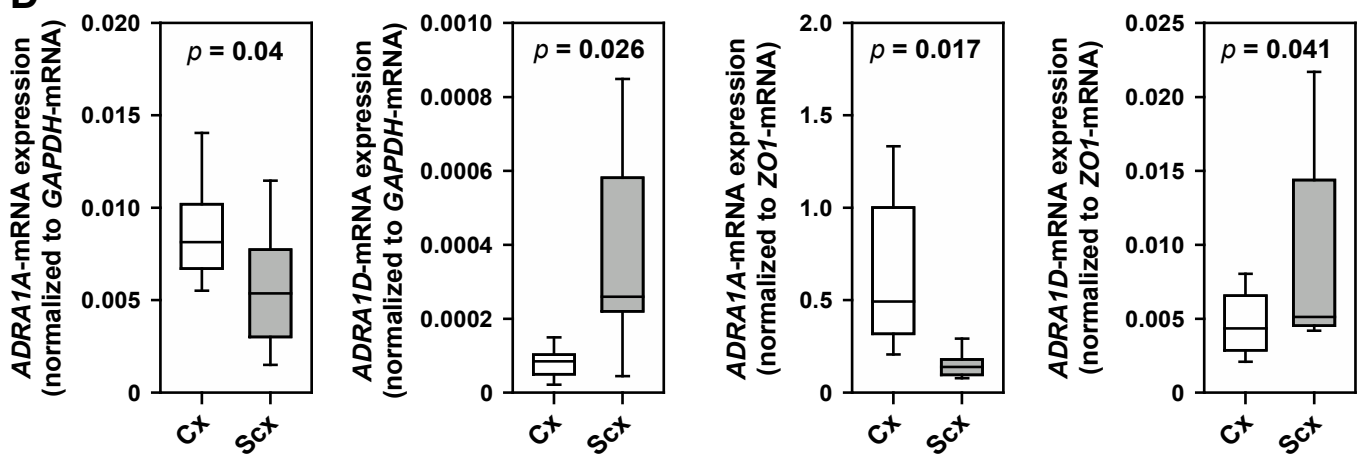

Figure 5. Expression of $\alpha 1$-adrenergic receptors in cortical and subcortical brain arterioles. (A) Western blot analysis was performed for cortical and subcortical brain arterioles from 14 sheep, as described in the methods section. $\alpha 1$-adrenergic receptors ( $\alpha 1-\mathrm{AR})$ are detectable in cortex $(\mathrm{Cx})$ and subcortex (Scx). 1-4, samples from different sheep; AU, arbitrary units; Ref., reference sample; (B) Quantification of receptor expression after normalization of band intensities to the housekeeping protein $\beta$-actin shows no differences of expression levels in cortex and subcortex, respectively; (C) Quantitative PCR-analysis was done using cDNA reverse transcribed from total RNA of 7 sheep. PCR-products of correct size were consistently detected for housekeeping genes GAPDH and $Z O-1$, and for the $\alpha 1$-adrenergic receptors $\mathrm{A}(A D R A 1 A)$ and $\mathrm{D}(A D R A 1 D)$, but not for the B-subtype receptor (ADRA1B). A, B, depict examples from two individual sheep; $\mathrm{H}_{2} \mathrm{O}$, no cDNA control; (D) Quantitation of receptor mRNA-expression in relation to the GAPDH $m R N A$ and the ZO-1 $m R N A$, respectively, by the $\Delta \Delta C_{\mathrm{t}}$-method. As some data sets were not normally distributed all quantitations are presented as box plots, where boxes represent 25 th and 75th percentiles, respectively. Medians are indicated by horizontal lines. Whiskers indicate 10th and 90th percentiles, respectively. $p$-values indicating significant differences are given in the panels.

\section{Discussion}

In this study, we identified differential regulation of cortical versus subcortical cerebral blood flow $(\mathrm{CBF})$ as a pathophysiological correlate to the greater vulnerability of the cerebral cortex in situations of severe blood loss.

\subsection{Clinical Implications}

Using the sheep model, we were able to continuously measure region-specific CBFs. During controlled hypovolemia, cortical CBF remained constant until a blood loss of $10 \%$ compared to subcortical CBF, which remained constant until a blood loss of $20 \%$. Even more important, the rate of reduction of $\mathrm{CBF}$ is more than three-fold higher in the cortex as compared to the subcortex, indicating that effective redistribution of blood flow is confined to the latter. It is known that the degree of the decrease of cerebral perfusion is correlated to the severity of brain damage [3]. Taken together, less pronounced redistribution may explain the higher frequency of hypoxic-ischemic brain damage in the cortex as compared to the subcortex of patients with hemorrhagic shock [7,9-12].

The varying degrees of CBF responses during controlled hemorrhage imply differences in the function of redistribution in the cerebral cortex and subcortex. This does not correspond to the present paradigm that centralization of the blood circulation spares the entire brain during adult life [20-23]. 
Indeed, there are some studies, which have shown heterogeneity in CBF in response to severe hemorrhage [13-16,24-27]. In summary, using small animal models (rats, rabbits, cats, newborn sheep or pigs) without or with anesthesia, various outcomes were reported. A trend can be delineated: the phylogenetically older subcortex or brainstem regions controlling fundamental functions (e.g., respiration and circulation) seemed to be better protected against hemorrhage (i.e., less decrease, maintenance or even increase of blood flow, depending on the system used). Most of these studies were done either with the iodoantipyrine method or with microspheres, which have the advantage of relatively good spatial resolution. A clear disadvantage of these methods is their lacking suitability for continuous monitoring studies.

Laser Doppler flowmetry allows continuous measurement of CBF [28,29]. Therefore, we used it in the sheep model, which provides more similarities to the human situation than small animals like rodents do [30]. Obviously, studies with a design similar to that which we used, i.e., massive blood removal, cannot be done in human subjects for ethical reasons. However, less severe experimental interventions also indicate that there are different regional CBF responses. In a study with conscious human subjects, Sato et al. described blood flow responses in the internal carotid artery and the vertebral artery using the ultrasound technique for measurements [31]. Most importantly, the reduction in blood pressure caused by a 60-degree head-up tilt resulted in a significant reduction of blood flow in the internal carotid artery, whereas blood flow was essentially unchanged in the vertebral artery. Moreover, they found regional differences in dynamic cerebral autoregulation during a thigh-cuff test [31]. Taken together, despite different experimental settings resulting in different severity of changes of blood pressure, there is clear evidence for region specific redistribution of CBF. In addition, these differences become manifest not only during orthostatic strain but also during extended periods of severe hemorrhage.

In our experimental setup, we tried to limit potential effects of asphyxia. Therefore, blood removal was carried out within $5 \mathrm{~min}$, so that a mere reduction in blood pressure with minimal effects on oxygen supply was ensured. However, even then a reduced $\mathrm{pO}_{2}$ with concomitant increase of lactate and decrease of $\mathrm{pH}$ reflects a shift to a more anaerobic metabolic condition despite centralization of the circulation. These findings are in agreement with former observations in the same model [32].

The insufficient protection of cortical CBF during hypovolemia may contribute to the higher vulnerability of the cerebral cortex to ischemic brain damage during hemorrhage [7,9]. Our results point out that maintenance of cortical CBF is essential in managing the bleeding patient to improve neurological outcome $[6,7,9]$. Moreover, our results emphasize that oxygen supply after hemorrhage may protect the brain from hypoxia as ventilation with $100 \%$ oxygen during controlled hypovolemia maintained oxygen saturation of the blood.

\subsection{Potential Roles of $\alpha 1$-Adrenergic Receptors}

Hemorrhage is known to induce sympathetic activation leading to contraction of blood vessels in order to counteract the drop in blood pressure. Sympathetic signaling also plays a major role in control of cerebral vascular tone and CBF [33]. Smooth muscle contraction is necessary to maintain or increase vascular tone, and $\alpha 1$-ARs are the most important players in generation of a contractile response (reviewed in $[34,35]$ ). The $\alpha 1$-AR subfamily of adrenergic receptors includes three members: $\alpha 1 \mathrm{~A}, \alpha 1 \mathrm{~B}$ and $\alpha 1 \mathrm{D}$. Arteries, which exhibit contractile responses to sympathetic stimulation express at least one $\alpha 1$-AR subtype [34-36]. However, the contractile response is dependent on various factors, e.g., receptor density, receptor internalization, desensitization, cell specific wiring of signal transduction pathways [34-37]. All three $\alpha 1$-AR subtypes were shown pharmacologically to be involved in mediation of contractile responses of cerebral artery rings from sheep [38]. The rationale for using urapidil for $\alpha 1 \mathrm{~A}$-adrenergic blockade followed the paradigm that $\alpha 1 \mathrm{~A}$-ARs mediate vasoconstriction after sympathetic activation. This is based on (i) the proven ability of urapidil to lower arterial blood pressure [39]; (ii) the selective inhibition of $\alpha 1 \mathrm{~A}-\mathrm{ARs}$ by urapidil [35,37]; and (iii) the proven role (by gene knock-out) of $\alpha 1 \mathrm{~A}-\mathrm{AR}$ in maintenance of arterial blood pressure [40]. Furthermore it has been 
shown previously that urapidil decreases vascular resistance in all tissues without affecting cardiac output [10] and does not affect baseline CBF [11,12]. From that, we hypothesized that cortical CBF might be preserved with urapidil treatment. To avoid interference by peripheral vasodilatation, we used a dosage, which did not modulate baseline MABP.

Subcortical CBF, but not cortical CBF, is largely maintained during controlled hypovolemia. At first glance this fits nicely with the higher expression levels of $\alpha 1 \mathrm{~A}$-ARs-mRNA in cortical arterioles and the generally accepted role of $\alpha 1 \mathrm{~A}$-ARs to mediate vasoconstriction. But in fact the comparison of cortical $\mathrm{CBF}$ without and with $\alpha 1 \mathrm{~A}$-adrenergic blockade suggests that $\alpha 1 \mathrm{~A}$-AR-signaling is necessary for the compensatory mechanism responsible for hyperperfusion when the blood volume is replenished. Furthermore, the redistribution capacity of the subcortex is severely blunted without sufficient $\alpha 1 \mathrm{~A}-\mathrm{AR}$-signaling. This indicates that $\alpha 1 \mathrm{~A}-\mathrm{AR}$-signaling provides at least a permissive signal for redistribution of $\mathrm{CBF}$ - but does not exclude a role in vasoconstriction either.

The observed effects of urapidil are also not consistent with the substance's known sympatholytic effect, which is mediated by central serotonin 5-HT1A receptors [39]. This effect should have manifested during the baseline measurements. In addition, a direct serotonergic effect of urapidil within the brain vessels also does not explain the prevention of maintenance of subcortical CBF, since the density of 5-HT1A receptors is lower in the thalamus than in the cerebral cortex [41-43].

Interestingly, part of the hyperperfusion during reperfusion of the subcortex is refractory to $\alpha 1 \mathrm{~A}-\mathrm{AR}$-blockade. We can only speculate, presently, whether the stronger expression of $\alpha 1 \mathrm{D}-\mathrm{ARs}$ or the weaker expression of $\alpha 1 \mathrm{~A}$-ARs in the subcortex, which we found at the level of mRNA-expression, may be responsible for the (higher) capacity for redistribution towards the subcortex.

Taken together, our physiological and expression data strongly suggest that in (at least part of) brain arterioles, the role of $\alpha 1$-ARs does not fit the present paradigm of a strictly vasoconstrictory function. This is not without precedent, as at least for the rat carotid artery it was shown previously that functional cross-talk with $\beta$-ARs can result in $\alpha 1 \mathrm{D}$-AR-mediated relaxation $[44,45]$. Therefore, it will be necessary to further define the receptors involved in redistribution to the subcortex with selective antagonists against various adrenergic receptors in future work.

Our assessment of $\alpha 1$-AR-expression at the protein level was hampered by the lack of subtype-specific antibodies, which recognize the sheep receptors. Therefore, we used only the anti-human pan-specific $\alpha 1-\mathrm{AR}$ antibody (see methods). The molecular weight of approximately $60 \mathrm{kDa}$ for the diffuse band detected by this antibody corresponds to the full-length $\alpha 1 \mathrm{D}$ receptor or to glycosylated $\alpha 1 \mathrm{~A}$ receptor isoforms, thus allowing no discrimination between the receptor subtypes. Consequently the notion of differential expression of $\alpha 1 \mathrm{~A}-\mathrm{AR}$ and $\alpha 1 \mathrm{D}-\mathrm{AR}$ in cortex and subcortex, respectively, is based on mRNA-quantification only. The normalization of expression levels to the endothelial cell marker ZO-1 allows the conclusion that, indeed, vascular $\alpha 1$-AR content differs between cortex and subcortex. As mentioned above, this differential receptor expression might indeed be responsible for the differential effects of hypovolemia on region-specific CBF. Whereas all $\alpha 1$-AR can activate several signal transduction pathways the potency of doing so varies widely [35-37]. The increase of intracellular $\mathrm{Ca}^{2+}$, which is a prerequisite of smooth muscle contraction necessary for vasoconstriction, is largest upon stimulation of the $\alpha 1 \mathrm{~A}-\mathrm{AR}[36,46]$. In contrast, the $\alpha 1 \mathrm{D}-\mathrm{AR}$ has the highest potential for activation of mitogen-activated protein kinase pathways [36,47]. Therefore, it is likely-and should be investigated in future studies - that differential activation of downstream signaling pathways is the key for elucidation of the molecular mechanisms underlying the differential regulation of cortical and subcortical CBF under conditions simulating severe shock.

\section{Materials and Methods}

\subsection{Surgical Instrumentation}

All procedures were approved by the Thuringia Animal Welfare Committee (Bad Langensalza; permission number: TVA 02-60/10; valid from 20 December 2010 until 20 December 2015) and 
conducted in accordance to the ARRIVE guidelines [48]. Thirteen female Merino-long wool sheep at 2-6 years of age weighing $94.5 \pm 9.2 \mathrm{~kg}$ were included in this study and underwent surgery. After food withdrawal for $24 \mathrm{~h}$, anesthesia was induced by intramuscular injection of $10-15 \mathrm{mg} \cdot \mathrm{kg}^{-1} \mathrm{ketamine}$ (Ketamin-Hydrochlorid ${ }^{\circledR}$, Pfizer, Berlin, Germany) and $0.2 \mathrm{mg} \cdot \mathrm{kg}^{-1}$ midazolam (Midazolam-Hameln ${ }^{\circledR}$, Hameln Pharmaceuticals, Hameln, Germany). After orotracheal intubation anesthesia was maintained by inhalation of $1.5 \%$ isoflurane (Isofluran-Actavis ${ }^{\circledR}$, Actavis, Langenfeld, Germany) in 100\% oxygen over the entire experiment. All ewes were instrumented with vascular catheters (Arterial Leadercath, Vygon, Aachen, Germany) inserted into the carotid artery for blood sampling and blood pressure measurement and into the jugular vein (Trilyse Expert ${ }^{\circledR}$, Vygon, Lansdale, PA, USA) for intraoperative administration of analgesics and removal of blood. Arterial blood pressure was recorded using transducers (Combitrans Transducer, Braun, Melsungen, Germany). Skin and epicranial aponeurosis were removed from the skull and a borehole trepanation of $1 \mathrm{~cm}$ in diameter was performed $4 \mathrm{~cm}$ in front of the interauricular line and $1 \mathrm{~cm}$ lateral of the midline. Single fiber laser Doppler flow probes (diameter $400 \mu \mathrm{m}$, Moor, Devon, UK) were inserted into the brain $2 \mathrm{~mm}$ to reach the parietal cortex and $2.7 \mathrm{~cm}$ to reach the subcortex (thalamus), respectively, for continuous monitoring of capillary CBF changes. Laser Doppler flowmetry is a reliable tool to assess dynamic changes in capillary cerebral perfusion continuously using the Doppler effect induced by moving red cells [49]. After a left lateral laparotomy we inserted a flow probe (Animal Blood Flowmeter T 206, Transonic, Ithaca, NY, USA) around the left kidney artery to determine renal blood flow (RBF) as a measure of the effects of blood loss on tissues severely affected by major hemorrhage. Electrocardiogram (ECG) was derived using intracutaneous wire electrodes. After the experiment animals were euthanized by intravenous injection of pentobarbital sodium (Narcoren, Merial, Halbergmoos, Germany).

\subsection{Hypovolemia and Reperfusion}

The experimental protocol consisted of $30 \mathrm{~min}$ baseline, $5 \mathrm{~min}$ controlled hemorrhage, $5 \mathrm{~min}$ lag time, $5 \mathrm{~min}$ reperfusion and $20 \mathrm{~min}$ recovery. After $30 \mathrm{~min}$ of baseline recordings, controlled severe hemorrhage was induced in seven sheep by withdrawal of $50 \%$ of the estimated total blood volume, which approximates $7 \%$ of total body weight in sheep $[3,41]$. Blood was removed continuously at a rate aiming to remove the estimated blood volume within five min. The blood was saved in heparinized (1000 I.E. Heparin-Natrium, Ratiopharm, Ulm, Germany) empty infusion bags and kept continuously at $37^{\circ} \mathrm{C}$ in a water bath. Five min after the withdrawal of $50 \%$ of the estimated total blood volume the total blood volume was replenished within five min and blood flow changes were monitored for an additional $20 \mathrm{~min}$. Cortical and subcortical CBF, MABP, ECG, HR, body temperature and oxygen saturation were recorded continuously during hypovolemia and reperfusion. Blood gas samples were taken before the start of the experimental procedure, at 50\% blood loss and at the end of the experiments.

\section{3. $\alpha 1$ A-Adrenergic Blockade}

The same experimental procedure was performed in six sheep under $\alpha 1 \mathrm{~A}$-adrenergic receptor blockade with urapidil (Urapidil-Phamore ${ }^{\circledR}$, Phamore, Ibbenbüren, Germany). An initial bolus of $8 \mathrm{mg}$ urapidil was injected after 10 min of baseline recordings, followed by continuous infusion at a rate of $8 \mathrm{mg} / \mathrm{h}$ over the remaining observation period. This dose was the maximal dose that did not affect MABP, HR and RBF in preliminary experiments.

\subsection{Sample Preparation and Western Blotting}

Brain arterioles from cortex and subcortex were taken after euthanasia from 14 age-matched control sheep that did not undergo the experimental procedure. 3rd branches of region specific arterioles were snap frozen in liquid nitrogen. Sample preparation and Western blotting protocol were described previously [30]. Briefly, an affinity-purified antibody raised against a peptide conserved in all human and sheep $\alpha 1$-adrenergic receptors ( $\alpha 1$-ARs) was used for detection of proteins (rabbit 
anti-pan- $\alpha 1-A R ; 1: 1000$; Acris Antibodies, Herford, Germany). Mouse anti- $\beta$-actin (1:5.000; AC-15, A5441; Sigma-Aldrich, Taufkirchen, Germany) was used for normalization. Secondary antibodies were goat anti-rabbit-IgG-HRP (1:5.000; sc-2004) and goat anti-mouse-IgG-HRP (1:5.000; sc-2031) (all from Santa Cruz Biotechnology, Dallas, TX, USA). For the comparison of $\alpha 1$-AR expression in different gels, a reference sample was included in each gel (produced by mixing nine brain vessel extracts).

\subsection{Quantitative RT-PCR}

Total RNA was extracted from cortex and thalamus of 8 sheep using NucleoSpin RNA (Macherey-Nagel, Düren, Germany), and reverse transcribed into cDNA using the High-Capacity cDNA Reverse Transcription Kit (AppliedBiosystems, Darmstadt, Germany). qRT-PCR was performed in a StepOnePlus cycler (Applied Biosystems) using GoTaq qPCR Master Mix (Promega, Mannheim, Germany), and the following primers (Gene symbol, forward primer, reverse primer): $A D R A 1 A$, 5'-ACTACATCGTCAACCTGGCG-3' , 5'-GGTAGCGCAGAGGATAGCTC-3'; ADRA1B, 5' -CCTTCAA GCTCTTGCCCGA-3' ${ }^{\prime}$, 5'-CCAGGGGCATGTTGCTTTG-3'; ADRA1D, 5' -CATTGTCGTGGGCGTCTT TG-3' 5' $^{\prime}$-TGTTGAAGTAGCCCAGCCAG-3'; GAPDH 5 $^{\prime}$-GAAGGTCGGAGTGAACGGAT-3', $5^{\prime}$-GAT GACGAGCTTCCCGTTCT-3' ; and ZO1, 5' -CTCCAGGCCCTTACCTTTCG-3' , 5' -CTCGTAAAGAGTC GGCGTGT- $3^{\prime}$. Relative expression levels of $\alpha 1$-adrenergic receptor mRNAs (ADRA1A, ADRA1B, $A D R A 1 D$ ) were analyzed using the $\triangle \triangle \mathrm{Ct}$ method, and normalized to either GAPDH as a marker for total cell mass or ZO1 as endothelial marker.

\subsection{Data Analysis}

Blood gases and lactate were measured on a standard clinical blood gas analyzer (ABL 600, Radiometer $\mathrm{GmbH}$, Willich, Germany). CBF was recorded using a laser Doppler flowmeter (DRT4, Moor, Devon, UK) as described previously [49]. CBF values are given in arbitrary units. All biophysical variables were amplified and sampled at $1000 \mathrm{~Hz}$ using a data acquisition and analysis system (Labchart Pro7, ADInstruments, Spechbach, Germany). MABP was calculated and HR was triggered from R waves continuously. Then, all parameters were averaged over five seconds.

\subsection{Statistical Analysis}

Descriptive statistics (means \pm SEM) were used to summarize the outcome parameters of the different measurements. Differences of outcome parameters versus the average of $30 \mathrm{~min}$ of baseline were identified using one way repeated measures ANOVA and Holm-Sidak multiple comparisons versus baseline. Pairwise comparisons were done with Student's $t$-test, or the paired $t$-test, as appropriate. The non-linear dependences of blood flow and blood pressure were fitted using three-parameter logistic regression. All statistical analyses were done with SigmaPlot 13.0 (Systat Software, Erkrath, Germany). $p$-Values of less than 0.05 were considered statistically significant.

\section{Conclusions}

In conclusion, subcortical but not cortical cerebral perfusion is maintained during hypovolemic shock. Maintenance of subcortical perfusion is dependent on $\alpha 1 \mathrm{~A}-\mathrm{AR}$-signaling, despite its lower expression in subcortical arterioles. Thus, our results suggest that the effectiveness of cerebral redistribution mechanisms under clinical relevant conditions such as during hemorrhagic shock is inferior in the phylogenetically younger cerebral cortex than in the phylogenetically older subcortex. In other words: the essential functions for survival are better protected than the higher brain functions.

Acknowledgments: We are grateful to Petra Dobermann, Simone Göbel, Dirk Hergt, Gabriele Grunert for skillful technical assistance and support, to Marius Nistor and Nasim Kroegel for language editing. The project was supported by the European Commission through the Seventh Framework Programme (FP7) No. 2799281.

Author Contributions: René Schiffner, Sabine Juliane Bischoff and Martin Schmidt designed the study, conducted most of the experiments, analyzed and interpreted the data, and drafted the manuscript; Thomas Lehmann did statistical analyses and interpreted data; Florian Rakers, Sven Rupprecht, Georg Matziolis, Harald Schubert, 
Matthias Schwab and Otmar Huber participated in the design of the study and critically discussed the concept and data; Juliane Reiche conducted mRNA-expression analysis and critically discussed the data. All authors read and approved the final manuscript.

Conflicts of Interest: The authors declare no conflict of interest.

\section{Abbreviations}

$\begin{array}{ll}\alpha 1-A R & \alpha 1 \text {-adrenergic receptor (at the protein level) } \\ \text { CBF } & \begin{array}{l}\text { cerebral blood flow } \\ \text { electrocardiogram }\end{array} \\ \text { ECG } & \text { heart rate } \\ \text { HR } & \text { mean arterial blood pressure } \\ \text { MABP } & \text { quantitative real-time polymerase chain-reaction } \\ \text { qRT-PCR } & \text { renal blood flow } \\ \text { RBF } & \text { sheep gene for adrenoceptor alpha 1A (GenBank accession number) } \\ \text { ADRA1A (NC_019459.2) } & \text { sheep gene for adrenoceptor alpha 1B (GenBank accession number) } \\ \text { ADRA1B (NC_019462.2) } & \text { sheep gene for adrenoceptor alpha 1D (GenBank accession number) } \\ \text { ADRA1D (NC_019470.2) } & \text { sheep gene for glyceraldehyde-3-phosphate dehydrogenase (GenBank } \\ \text { GAPDH (NC_019460.2) } & \text { accession number) } \\ \text { ZO1 (NC_019475.2) } & \text { sheep gene for tight junction protein 1 (GenBank accession number) }\end{array}$

\section{References}

1. Kauvar, D.S.; Lefering, R.; Wade, C.E. Impact of hemorrhage on trauma outcome: An overview of epidemiology, clinical presentations, and therapeutic considerations. J. Trauma 2006, 60, 3-11. [CrossRef] [PubMed]

2. Murray, C.J.; Vos, T.; Lozano, R.; Naghavi, M.; Flaxman, A.D.; Michaud, C.; Ezzati, M.; Shibuya, K.; Salomon, J.A.; et al. Disability-adjusted life years (DALYs) for 291 diseases and injuries in 21 regions, 1990-2010: A systematic analysis for the Global Burden of Disease Study 2010. Lancet 2012, 380, 2197-2223. [CrossRef]

3. Gutierrez, G.; Reines, H.D.; Wulf-Gutierrez, M.E. Clinical review: Hemorrhagic shock. Crit. Care 2004, 8, 373-381. [CrossRef] [PubMed]

4. Schiffner, R.; Antonow-Schlorke, I.; Mueller, T.; Frasch, M.; Rupprecht, S.; Schubert, H.; Schwab, M. Potential importance of alpha-receptors for distribution of cerebral blood flow (CBF) during umbilical cord occlusion (UCO) in fetal sheep-effects of betamethasone (BM). Reprod. Sci. 2010, 17, 300.

5. Shevell, T.; Malone, F.D. Management of obstetric hemorrhage. Semin. Perinatol. 2003, 27, 86-104. [CrossRef] [PubMed]

6. Kudo, Y.; Ohtaki, H.; Dohi, K.; Yin, L.; Nakamachi, T.; Endo, S.; Yofu, S.; Hiraizumi, Y.; Miyaoka, H.; Shioda, S. Neuronal damage in rat brain and spinal cord after cardiac arrest and massive hemorrhagic shock. Crit. Care Med. 2006, 34, 2820-2826. [CrossRef] [PubMed]

7. Heckbert, S.R.; Vedder, N.B.; Hoffman, W.; Winn, R.K.; Hudson, L.D.; Jurkovich, G.J.; Copass, M.K.; Harlan, J.M.; Rice, C.L.; Maier, R.V. Outcome after hemorrhagic shock in trauma patients. J. Trauma 1998, 45, 545-549. [CrossRef] [PubMed]

8. Peterson, E.; Chesnut, R.M. Static autoregulation is intact in majority of patients with severe traumatic brain injury. J. Trauma 2009, 67, 944-949. [CrossRef] [PubMed]

9. Thebaud, B.; Husson, B.; Navelet, Y.; Huault, G.; Landrieu, P.; Devictor, D.; Sebire, G. Haemorrhagic shock and encephalopathy syndrome: Neurological course and predictors of outcome. Intensive Care Med. 1999, 25, 293-299. [CrossRef] [PubMed]

10. Pegram, B.L.; Kobrin, I.; Natsume, T.; Gallo, A.J.; Frohlich, E.D. Systemic and regional hemodynamic effects of acute and prolonged treatment with urapidil or prazosin in normotensive and spontaneously hypertensive rats. Am. J. Med. 1984, 77, 64-73. [CrossRef]

11. Puchstein, C. Treatment of hypertensive crises in neurosurgery. Ann. Fr. Anesth. Reanim. 1989, 8, 598-602. [CrossRef] 
12. Kick, O.; van Aken, H.; Wouters, P.F.; Verbesselt, K.; van Hemelrijck, J. Vital organ blood flow during deliberate hypotension in dogs. Anesth. Analg. 1993, 77, 737-742. [CrossRef] [PubMed]

13. Waschke, K.F.; Riedel, M.; Lenz, C.; Albrecht, D.M.; van Ackern, K.; Kuschinsky, W. Regional heterogeneity of cerebral blood flow response to graded pressure-controlled hemorrhage. J. Trauma 2004, 56, 591-603. [CrossRef] [PubMed]

14. Bauer, R.; Hoyer, D.; Walter, B.; Gaser, E.; Kluge, H.; Zwiener, U. Changed systemic and cerebral hemodynamics and oxygen supply due to gradual hemorrhagic hypotension induced by an external PID-controller in newborn swine. Exp. Toxicol. Pathol. 1997, 49, 469-476. [CrossRef]

15. DeWitt, D.S.; Prough, D.S.; Taylor, C.L.; Whitley, J.M.; Deal, D.D.; Vines, S.M. Regional cerebrovascular responses to progressive hypotension after traumatic brain injury in cats. Am. J. Physiol. 1992, 263, 1276-1284.

16. Sadoshima, S.; Heistad, D.D. Regional cerebral blood flow during hypotension in normotensive and stroke-prone spontaneously hypertensive rats: Effect of sympathetic denervation. Stroke J. Cereb. Circ. 1983, 14, 575-579. [CrossRef]

17. Bond, R.F.; Johnson, G. Cardiovascular adrenoreceptor balance during hemorrhagic hypotension and shock. Circ. Shock 1985, 16, 155-164. [PubMed]

18. Rosenblum, W.I.; Chen, M. Density of perivascular nerves on some cerebral and extracerebral blood-vessels. Blood Vessels 1976, 13, 374-378. [CrossRef] [PubMed]

19. Meldrum, D.R.; Cleveland, J.C.; Meng, X.Z.; Sheridan, B.C.; Banerjee, A.; Harken, A.H. Hemorrhage induces acute cardioadaptation to ischemia-reperfusion by an $\alpha 1$-adrenoceptor-mediated, protein synthesisindependent mechanism. Am. J. Physiol. 1997, 272, 718-725.

20. Ogoh, S.; Hirasawa, A.; Raven, P.B.; Rebuffat, T.; Denise, P.; Lericollais, R.; Sugawara, J.; Normand, H. Effect of an acute increase in central blood volume on cerebral hemodynamics. Am. J. Physiol. 2015, 309, 902-911. [CrossRef] [PubMed]

21. Ogoh, S.; Hirasawa, A.; Sugawara, J.; Nakahara, H.; Ueda, S.; Shoemaker, J.K.; Miyamoto, T. The effect of an acute increase in central blood volume on the response of cerebral blood flow to acute hypotension. J. Appl. Physiol. 2015, 119, 527-533. [CrossRef] [PubMed]

22. Meng, L.Z.; Hou, W.G.; Chui, J.; Han, R.Q.; Gelb, A.W. Cardiac output and cerebral blood flow. Anesthesiology 2015, 123, 1198-1208. [CrossRef] [PubMed]

23. Koller, A.; Toth, P. Contribution of flow-dependent vasomotor mechanisms to the autoregulation of cerebral blood flow. J. Vasc. Res. 2012, 49, 375-389. [CrossRef] [PubMed]

24. Niwa, K.; Takizawa, S.; Takagi, S.; Shinohara, Y. Mild hypothermia disturbs regional cerebrovascular autoregulation in awake rats. Brain Res. 1998, 789, 68-73. [CrossRef]

25. Tuor, U.I.; Grewal, D. Autoregulation of cerebral blood flow: Influence of local brain development and postnatal age. Am. J. Physiol. 1994, 267, 2220-2228.

26. Mueller, S.M.; Heistad, D.D.; Marcus, M.L. Total and regional cerebral blood flow during hypotension, hypertension, and hypocapnia. Effect of sympathetic denervation in dogs. Circ. Res. 1977, 41, 350-356. [CrossRef] [PubMed]

27. Komjati, K.; Sandor, P.; Reivich, M.; Greenberg, J.H.; Kovach, A.G.; Jaggi, J.L.; Nyary, I. Regional heterogeneity and differential vulnerability of cerebral and spinal vascular $\mathrm{CO}_{2}$-responsiveness during graded haemorrhagic hypotension. Acta Physiol. Hung. 1996, 84, 229-249. [PubMed]

28. Dirnagl, U.; Kaplan, B.; Jacewicz, M.; Pulsinelli, W. Continuous measurement of cerebral cortical blood flow by laser-Doppler flowmetry in a rat stroke model. J. Cereb. Blood Flow Metab. 1989, 9, 589-596. [CrossRef] [PubMed]

29. Fabricius, M.; Lauritzen, M. Laser-Doppler evaluation of rat brain microcirculation: Comparison with the [14C]-iodoantipyrine method suggests discordance during cerebral blood flow increases. J. Cereb. Blood Flow Metab. 1996, 16, 156-161. [CrossRef] [PubMed]

30. Bischoff, S.J.; Schmidt, M.; Lehmann, T.; Irintchev, A.; Schubert, H.; Jung, C.; Schwab, M.; Huber, O.; Matziolis, G.; Schiffner, R. Increase of cortical cerebral blood flow and further cerebral microcirculatory effects of Serelaxin in a sheep model. Am. J. Physiol. 2016, 311, 613-620. [CrossRef] [PubMed]

31. Sato, K.; Fisher, J.P.; Seifert, T.; Overgaard, M.; Secher, N.; Ogoh, S. Blood flow in internal carotid and vertebral arteries during orthostatic stress. Exp. Physiol. 2012, 97, 1272-1280. [CrossRef] [PubMed]

32. Garnett, A.R.; Glauser, F.L.; Ornato, J.P. Hypercarbic arterial acidemia following resuscitation from severe hemorrhagic shock. Resuscitation 1989, 17, 55-61. [CrossRef] 
33. Mccalden, T.A. Sympathetic control of the cerebral-circulation. J. Auton. Pharmacol. 1981, 1, 421-431. [CrossRef] [PubMed]

34. Chen, Z.J.; Minneman, K.P. Recent progress in $\alpha 1$-adrenergic receptor research. Acta Pharmacol. Sin. 2005, 26, 1281-1287. [CrossRef] [PubMed]

35. Piascik, M.T.; Perez, D.M. $\alpha 1$-adrenergic receptors: New insights and directions. J. Pharmacol. Exp. Ther. 2001, 298, 403-410. [PubMed]

36. Hein, P.; Michel, M.C. Signal transduction and regulation: Are all $\alpha 1$-adrenergic receptor subtypes created equal? Biochem. Pharmacol. 2007, 73, 1097-1106. [CrossRef] [PubMed]

37. Koshimizu, T.; Yamauchi, J.; Hirasawa, A.; Tanoue, A.; Tsujimoto, G. Recent progress in $\alpha 1$-adrenoceptor pharmacology. Biol. Pharm. Bull 2002, 25, 401-408. [CrossRef] [PubMed]

38. Goyal, R.; Mittal, A.; Chu, N.N.; Zhang, L.B.; Longo, L.D. $\alpha 1$-Adrenergic receptor subtype function in fetal and adult cerebral arteries. Am. J. Physiol. 2010, 298, 1797-1806.

39. Buch, J. Urapidil, a dual-acting antihypertensive agent: Current usage considerations. Adv. Ther. 2010, 27, 426-443. [CrossRef] [PubMed]

40. Rokosh, D.G.; Simpson, P.C. Knockout of the $\alpha 1 \mathrm{~A} / \mathrm{C}$-adrenergic receptor subtype: The $\alpha 1 \mathrm{~A} / \mathrm{C}$ is expressed in resistance arteries and is required to maintain arterial blood pressure. Proc. Natl. Acad. Sci. USA 2002, 99, 9474-9479. [CrossRef] [PubMed]

41. Marcinkiewicz, M.; Verge, D.; Gozlan, H.; Pichat, L.; Hamon, M. Autoradiographic evidence for the heterogeneity of 5-HT1 sites in the rat brain. Brain Res. 1984, 291, 159-163. [CrossRef]

42. Lanfumey, L.; Hamon, M. Central 5-HT1A receptors: Regional distribution and functional characteristics. Nucl. Med. Biol. 2000, 27, 429-435. [CrossRef]

43. Barnes, J.M.; Costall, B.; Coughlan, J.; Domeney, A.M.; Gerrard, P.A.; Kelly, M.E.; Naylor, R.J.; Onaivi, E.S.; Tomkins, D.M.; Tyers, M.B. The effects of ondansetron, a 5-HT3 receptor antagonist, on cognition in rodents and primates. Pharmacol. Biochem. Behav. 1990, 35, 955-962. [CrossRef]

44. De Andrade, C.R.; Fukada, S.Y.; Olivon, V.C.; de Godoy, M.A.; Haddad, R.; Eberlin, M.N.; Cunha, F.Q.; de Souza, H.P.; Laurindo, F.R.; de Oliveira, A.M. $\alpha 1 \mathrm{D}$-adrenoceptor-induced relaxation on rat carotid artery is impaired during the endothelial dysfunction evoked in the early stages of hyperhomocysteinemia. Eur. J. Pharmacol. 2006, 543, 83-91. [CrossRef] [PubMed]

45. Pernomian, L.; Gomes, M.S.; Restini, C.B.; Pupo, A.S.; de Oliveira, A.M. Cross-talk with $\beta 2$-adrenoceptors enhances ligand affinity properties from endothelial $\alpha 1 \mathrm{D}$-adrenoceptors that mediates carotid relaxation. J. Pharm. Pharmacol. 2013, 65, 1337-1346. [CrossRef] [PubMed]

46. Taguchi, K.; Yang, M.; Goepel, M.; Michel, M.C. Comparison of human $\alpha 1$-adrenoceptor subtype coupling to protein kinase C activation and related signalling pathways. NS Arch. Pharmacol. 1998, 357, 100-110. [CrossRef]

47. Keffel, S.; Alexandrov, A.; Goepel, M.; Michel, M.C. $\alpha 1$-Adrenoceptor subtypes differentially couple to growth promotion and inhibition in Chinese hamster ovary cells. Biochem. Biophys. Res. Commun. 2000, 272, 906-911. [CrossRef] [PubMed]

48. Institute of Laboratory Animal Resources (U.S.); Committee on Care and Use of Laboratory Animals. Guide for the care and use of laboratory animals. In NIH Publication; U.S. Department of Health and Human Services, Public Health Service: Bethesda, MD, USA, 2011.

49. Muller, T.; Lohle, M.; Schubert, H.; Bauer, R.; Wicher, C.; Antonow-Schlorke, I.; Sliwka, U.; Nathanielsz, P.W.; Schwab, M. Developmental changes in cerebral autoregulatory capacity in the fetal sheep parietal cortex. J. Physiol. 2002, 539, 957-967. [CrossRef] [PubMed]

(C) 2017 by the authors. Licensee MDPI, Basel, Switzerland. This article is an open access article distributed under the terms and conditions of the Creative Commons Attribution (CC BY) license (http://creativecommons.org/licenses/by/4.0/). 